\title{
Tensions in Online Communities: The Case of a Mass Size eParticipation Initiative
}

\author{
Alessio Maria Braccini ${ }^{1,}$, Tommaso Federici ${ }^{1,}$ and $\varnothing y$ stein $\mathrm{S} æ b \varnothing^{2}$ \\ ${ }^{1}$ Department of Economics and Entrepreneurship, University of Tuscia, Viterbo, Italy \\ ${ }^{2}$ Department of Information Systems, University of Agder, Kristiansand, Norway \\ \{abraccini, tfederici\}@unitus.it, oystein.saboauia.no
}

\begin{abstract}
While Online Communities (OCs) are increasingly used to involve people in organizations and societies, few studies focus on how OC influence political decision making within eParticipation initiatives. This issue is explored through an interpretive case-study of the Italian Five Star Movement (M5S), a mass-size eParticipation political initiative recently founded by private citizens. The use of OCs is a common strategy to involve groups of people to easily connect on-line, cooperating on common and shared interests. We here focus on understanding the internal and external forces influencing on the OCs, to better understand how to manage such OCs within the eParticipation domain. We do so by introducing the concept of tensions, to describe the states that these contrasting forces produce on the OCs, addressing the research question: what tensions occur in OCs for eParticipation? Our work contributes to a deeper understanding of the OCs phenomenon within the eParticipation domain, while also provides avenues for further research.
\end{abstract}

Keywords. Tensions, Online Communities, eParticipation, eGovernment, Five Start Movement

\section{Introduction and motivation}

Information and communication technologies (ICT) are increasingly being adopted to involve citizens in decision-making processes $[1,2]$ to recapture citizens' declining interest in politics. Research in the eParticipation area focuses on the identification of the processes and structures through which ICT supports the relationship between citizens, governments and public bodies [3, 4]. A vast majority of eParticipation studies focuses on the use of ICT in conjunction with traditional communication channels [5]. Only few of these eParticipation initiatives have achieved their intended aims [6], and many remain local or small-scale [1].

In this landscape, the Italian Five Star Movement's (M5S) uses an OC to encourage direct citizens' participation in politics, and represents an exceptional example for several reasons [7, 8]. First, the daily collective activities and decisions may engage online several thousand participants (even up to 40,000). M5S is hence among the largest eParticipation projects in Europe. Second, the M5S was initiated from outside of the 
established elite as a protest organizations by initiators not being part of a traditional political system. Their online activities are really the core of their acting, not only something added on top of a traditional party's activities (like most eParticipation projects are). Third, all their decisions at the national level are made through processes performed online, making the OC's role central and eParticipation real. Finally, their success in attracting a large group of members to actively participate online seems to inspire similar kind of initiatives, in countries like Spain, Greece and Iceland.

The use of OC is a common strategy to involve groups of people to easily connect on-line, cooperating on common and shared interests [9]. However OCs are not stable entities [10]. OCs are under the effect of internal and external forces. The literature uses the concept of tension to describe the unstable conditions that these forces produce into the OCs $[9,11]$. Tensions are inevitable for an OC, being produced and reproduced by their very nature [12] through the continuous co-presence of both the individual and the communal dimension [13]. Resources flow discontinuously inside communities, and at any moment there are alternative and competing possibilities for decisions, objectives, aims, and actions in the OC $[9,10]$.

Being inevitable, tensions cannot be resolved permanently, but should be managed [9] to allow an OC for eParticipation to achieve its aims. Since few researchers have addressed the issue of governing tensions in OC [9, 14], and fewer within the eParticipation domain $[8,15]$, we identify and discuss in this paper tensions within OCs for eParticipation purposes. Our work is motivated by the following research question: which tensions occur in OCs for eParticipation? The main contribution from our work is a better understanding of the role of tension within OCs in eParticipation project. Based on the identification of tensions and the discussion of how they influence an OC for eParticipation, we contribute by suggesting implications for practice and avenues for further research.

The rest of the paper is organised as follows: first, we introduce the theoretical premises for our work: OCs and tensions. Then, before introducing our results, we briefly present the research context and approach. We conclude by discussing our findings and providing implications for practice and trajectories for future research.

\section{Theoretical Background}

\subsection{Online Communities}

Internet and ICT are becoming more and more pervasive, reaching an enlarging share of the world population, and continuously providing new opportunities and new challenges to individuals and organizations. ICT make resources sharing, information diffusion, and cooperation among groups of people who have sporadic physical contacts easy [16], giving rise to OCs that affect actions and behaviours of individuals, teams, and organizations [10].

The relevance of OCs is still under dispute. On the one side, we observe OCs being used by individuals, teams and organizations to work and cooperate in a hitherto unseen manner, affording for flexibility, increased absorptive capacity, participated knowledge 
generation and circulation, empowered capability to pursue communal objectives together. On the other side, OCs form detached virtual worlds where people live in a bubble based on alternative facts and reality.

OCs are persistent collections of people who share common interests and goals, and who mainly communicate through the Internet [17]. In an OC members cooperate on, if, and when, they agree that this is better for them and for the OC itself [18] to solve issues they could otherwise not solve individually [19]. OCs are built for a variety of purposes, such as managing relations with customers and partners $[20,21]$ cooperating on knowledge generation $[9,10]$, or sharing information of public interest [22]. The communication flows through digital channels used by the OC to enable the collective action of members [23]. Structuring and managing the community to stimulate group actions and avoid the adverse outcome of independent actions is challenging [24]. Inside the community there is a coexistence of an individual and a collective rationality [12], which poses challenges to the actual realization of a collective action of the community where the communal objective prevails over individual goals.

\subsection{Tensions in Online Communities}

Few research studied tensions in OCs and how to manage them, as well as the consequences for the survival of the community itself $[9,13,14,25]$. The concept of tension is used by the literature to define difficulties, internal or external to the community, or unstable conditions, oscillating between two different and competing states that the community should address to ensure community survival over time [9]. The tensions in OCs have been studied mainly at the level of community members' behaviour, possibly discussing the consequences that individual behaviours produce on the community itself.

Communications flow inside the OCs, and the related tensions that they might develop, are relevant for the community survival. Two different souls live in OCs: that of the individual, and that of the group. These two perspectives do not necessarily coincide, as what is good for the individual may not be good for the group. The opposite is also true. This produces consequences on individual and community decisions, generating tensions [12]. One intrinsic consequence to this regard is the tension generated by the conflict of communal versus individual orientation of the community. According to von Krogh et al. [26], the interaction of individuals and institutions inside OCs produce two different kinds of resources: internal and external. Internal resources are property of the individual, while external resources are public goods in the community. The production of internal and external resources always takes place concurrently, hence the tension between the communal versus the individual is unavoidable.

Given the continuously changing state of OCs, due to ebb and flow of resources [9], and to the competition between the communal and the private orientation $[12,26]$ tensions produce and reproduce continuously in the community. The literature agrees that tensions in OCs are not problems to be avoided, but rather enduring conditions that reproduce continuously. As a consequence, OCs' can only manage these tensions, and not solve them permanently $[9,27]$. Such tension management would require the OC to act ambidextrously $[14,28]$, because not necessarily one aspect of the tension is 
desirable and the other is not desirable. Moreover, further tensions than those discussed by the literature, might be present in OCs [9]. When used for eParticipation strategies, the openness of OCs frictions with the strictures of institutional participation processes, and specific tensions arise also in such cases [7].

\section{$3 \quad$ Research Design}

The empirical setting investigated is that of the M5S, an Italian political movement born from an $\mathrm{OC}$ that uses this $\mathrm{OC}$ to involve citizens directly in the action of political institutions.

\subsection{Case context}

The M5S is an Italian political movement that sharply distinguishes itself from traditional Italian parties. One of the main differences is that most activities related to the dissemination of political information, consultation, and decision-making processes are performed through online tools to promote citizens' involvement and participation in political processes. As an association, the M5S was established in 2009, building upon the community born since 2005 around the blog of Beppe Grillo, one of the founders and prominent member of the movement [29]. The M5S grew up throughout the years connecting an increasing number of people, and at the national elections in 2013 was the second most-voted party.

The OC is formed by people who follow the movement on-line. A subset of them also subscribe to the OC. Subscription is a voluntary process performed online, and is mandatory to fully participate to the collective action of the OC. Applications are evaluated and approved by the M5S staff. Upon approvals, applicants are 'certified' and have full access to the M5S OC. Applicants who are 'not yet certified' have their subscription on a pending status, and have limited access to the community in the form of restricted actions they are entitled to perform online. At the time of the data collection, the M5S OC connected about 100,000 certified subscribers, with 30,000-40,000 on average participating to online activities, and with 700,000 more subscriptions on a pending status.

The M5S OC is double layered: all members share the same tools and rules at the central national level, while at the local level members are organized in groups active across Italian territories, where every group chooses its own tools and adopts its own rules. People continuously interact with representatives, contributing to their work. Representatives are at the same time OC members, and sit it in institutions: since they are strictly obliged to follow OC decisions, they are named internally 'spokespersons'.

\subsection{Data collection and analysis}

The empirical setting was investigated through a qualitative research strategy with semi-structured interviews (approximately 13 hours of recorded material) and archival 
data (internal documents, web pages, and observations of online platforms). We conducted nineteen interviews with different members of the OC. We interviewed members across two different towns' local groups, representatives sitting in the national parliament and in regional councils. Interviewees were distributed among what we identified as the three characteristics figures of stakeholders:

- Nine M5S representatives, among parliamentarians and councillors at regional and municipal level (entitled REP in the empirical section);

- Seven certified subscribers (SUB) of the M5S, from either local group;

- Three voters (VOT), who being non-subscriber declared to have voted for the M5S in the 2013 elections of the national parliament.

Based on a common interview track slightly adapted to meet each figure's point of view, interviewees were asked to report on difficulties within the M5S OC, and in the interplay between such community and the organizational setting of the institutions (e.g. councils of municipalities, regional parliament, and national parliament) in which representatives of the M5S sit and operate. The interviews were recorded, transcribed and analysed individually by the authors, who iteratively discussed the results of their individual analyses to compose a mutually agreed-upon interpretation. Archival data and observations data were also included and triangulated [30] to strengthen the relevance of the knowledge gleaned from interviews, archival data, and used ICT tools.

Following a grounded theory approach [31], the research team identified tensions letting them emerge from the data without adhering to any a priori constructs. The resulting ideas were later analysed considering current related literature to identify how the study added to existing research.

\section{$4 \quad$ Empirical Evidences}

We will here report findings related to the overall ideas of how tensions work in the M5S, before we summarize tensions identified through our analyses.

The M5S' main objective is to achieve direct citizen involvement in the decisionmaking processes of political institutions, to allow them to contribute to the generation of knowledge and decision-making processes. Our interviewees reported difficulties in such interplay, ascribed to OC members' lack of technical expertise in the issues discussed, and in the difference among values, rules, and routines between the community and the organizational setting of the political institution. For example, the M5S uses a system designed to collectively engage citizens in the co-production of law texts that M5S' representatives should propose in the institutions. The representatives reported the difficulties to use direct citizens' input, as the average citizen often lacks contextual and procedural knowledge which are instead required by the formal processes of the institution:

'We have many problems with this kind of approach, which is really impacting; it is really creating fights and battles with the traditional system because the rules are not built to bring the people in the institutions directly' (REP1)

Another consequence concerns the volume of information generated using ICT: the 
produced pieces of information do not have a proper structure or organization, and this complicates the life of community members to contribute to the discussions and decision making. At the same time, the knowledge generation processes are not strictly focused to support representatives' needs, making it difficult to identify the contents that are useful for their work. Whereas ICT might facilitate a paradigm shift that will make organising collective actions more efficient [32], the example of the M5S illustrates the tension arising from the massive amount of content generated:

'The time constraint restricts my work. I had the ability to vote, but out of 800 candidates, I read about 400 CVs. I couldn't actually read all of them.' (SUB1)

'I cannot read 1,000 suggestions every day and understand which is best.' (REP2)

The M5S OC builds strongly on the potential advantages of reduced transaction costs to connect people and fluidity in team organization, leaving, by intention, groups free to self-organize in the OC. The M5S adopts a flat structure, with a limited set of rules and regulations, allowing members to freely organise in teams. At the same time, this makes the coordination of actions of OC's members more difficult. The structure of the OC follows a double-loop design, consisting of a structured core and a flexible periphery. The organic nature of the periphery is showed by the freedom to choose and change routines, rules, and coordination technologies, to bypass rules, and to change the mind on these aspects several times over time:

'The best tool will survive. We leave really to the activists the freedom to develop the best tool. It is our philosophy.' (REP1)

'When you set a regulation, you do not have to power off your brain. We have this regulation that forces us to rotate regulations but this guy has been working for two years in managing Twitter. Rationally, I would say: ok for the regulation, ok for the rotation, but he can do this and it would be a stupid thing to change this.' (SUB2)

The mechanic structure is at the central level, where the mediating technologies are more enforcing, improvisation is not possible (the technologies common to all OC are designed and deployed by the movement staff, and not by community members), and access is regulated by norms established by the movement.

In the frontier of interaction between the community and the institution, the clash on values, rules, and routines produces tensions. The presence of these tensions is witnessed by the mutual attempt of the OC and of the organizational setting of the institution to impose or extend their values, rules and routines on the other. The working dynamics in institutions rely on the delegations to the representatives, and create a divide with common practices, based on continue interaction with members and the sharing of decision-making of the M5S. They receive pressure from the institution, henceforth they try to impose their view on the organizational setting of the institution:

'We have many pressures [...] and it is not easy to keep our values because we have many bad influences. The political systems are trying to change us, I have many pressures from other parties to become like others, to change our values, 
to create alliances or collaboration that will change us [...] but at the same time we are trying to change the system from the outside.' (REP1)

The tensions arising between the community and the institutions might be an underpinning cause of the decay of the relationship between these two entities. The difficulties in letting the community easily interoperate with other organizations might influence on the individuals' motivation to stay within the OC, since members may find it difficult to identify how institutions are influenced by their individual contributions within the OC. The same might hold true from the other side, where the value of relying on the $\mathrm{OC}$ to reduce the costs of managing the relationships with stakeholders might be lower than the efforts needed to make sense of the contributions from OC.

\section{$5 \quad$ Analysing evidences}

Based on the analysis of the M5S OC, we identified eight tensions. They are briefly introduced in table 1 and further discussed below.

At any given moment, an $\mathrm{OC}$ can be in a state resulting from the tension between Inertia and Action. People inside the OC might act to achieve the objectives of the community, or they might do nothing, resulting in an OC remaining silent and inactive.

The activity of the community is subject to the influence of the tension between Content vs Garbage. OC are goal-oriented entities. When actions take place, they could generate targeted and useful contents in relation to the goal, or a mass of contents (here defined as garbage) not useful or not manageable for the aim of the OC. This condition is enforced in the case of OCs for eParticipation, where members are called to produce content.

An OC for eParticipation is a collection of people using Internet to achieve OC's aims, then sharing with everybody information and processes. While this is an opportunity for OC of showing in detail its action, it is also a way to disclose to other subjects plans and strategies, which may not be always convenient. There is a potential tension in finding the balance between the level of confidentiality in OC actions (Private) and the level of openness (Public) in the OC actions.

Action takes place in an $\mathrm{OC}$ for eParticipation and its sub-groups, which operate at a different level, being oriented to a specific territory or topic. If sub-groups are present, their actions may proceed according to common rules and using the same tools of the entire community, or instead the sub-community may adopt its own rules and tools. To this regard, OCs are subjects to tension between the internal Groups and the entire community (Whole).

Contents production may be open to all, when everyone may contribute to OC's action. In this case, an $\mathrm{OC}$ for eParticipation works just like a speaker's corner: whoever has something to tell may do so. On the contrary, OC may have rigid rules and standard procedures for allowing members to contribute, where members are required to fulfil programs and procedures before their contributions are accepted. OCs are hence impacted by a tension we have named Speaker's Corner vs Conference. 
Table 1. Tensions within the OC

\begin{tabular}{|c|c|c|}
\hline & Tension & Definition \\
\hline 1 & $\begin{array}{l}\text { INERTIA vs } \\
\text { ACTION }\end{array}$ & $\begin{array}{l}\text { OC can be in the tension between the inertia (when people are not } \\
\text { acting or doing nothing), and action (where people are taking ac- } \\
\text { tions in the community). }\end{array}$ \\
\hline 2 & $\begin{array}{l}\text { CONTENT vs } \\
\text { GARBAGE }\end{array}$ & $\begin{array}{l}\text { Interaction among members in the OC is targeted to achieve a spe- } \\
\text { cific outcome (i.e. a decision, the production of a knowledge asset). } \\
\text { In any given moment, the community can rely on useful contents } \\
\text { and then it moves towards this target, or be immersed in loads of } \\
\text { useless contributes (garbage) and it drifts without a specific route. }\end{array}$ \\
\hline 3 & $\begin{array}{l}\text { PUBLIC vs } \\
\text { PRIVATE } \\
\text { ACTION }\end{array}$ & $\begin{array}{l}\text { The use of internet technologies may lead the OC to reveal infor- } \\
\text { mation to the external environment or not. Hence, there is a poten- } \\
\text { tial tension related to the level of openness (public actions) and the } \\
\text { level of confidentiality (private actions). }\end{array}$ \\
\hline 4 & $\begin{array}{l}\text { GROUPS vs } \\
\text { WHOLE }\end{array}$ & $\begin{array}{l}\text { An OC is not a monolithic entity, but is composed by sub-groups. } \\
\text { These sub-groups live inside the community sharing the same envi- } \\
\text { ronment, but may also create micro-environments. It arises a ten- } \\
\text { sion when norms, values, processes or tools of the OC clash with } \\
\text { that of the sub-groups. }\end{array}$ \\
\hline 5 & $\begin{array}{l}\text { SPEAKER'S } \\
\text { CORNER vs } \\
\text { CONFERENCE }\end{array}$ & $\begin{array}{l}\text { The tension is about the possibility to allow anybody to participate } \\
\text { to the OC, contradicted by the possibility of restricting the partici- } \\
\text { pation based on selection processes. }\end{array}$ \\
\hline 6 & $\begin{array}{l}\text { TRANSPARENT } \\
\text { vs OBSCURE }\end{array}$ & $\begin{array}{l}\text { There is a tension between transparency, where information on } \\
\text { roles, rules and activities are communicated openly and explicitly } \\
\text { to everyone, and obscurity, where such information may be only } \\
\text { implicitly, indirectly and vaguely communicated. }\end{array}$ \\
\hline 7 & $\begin{array}{l}\text { LIQUID vs } \\
\text { SOLID }\end{array}$ & $\begin{array}{l}\text { The tension here arises by the contrasting needs of keeping the OC } \\
\text { liquid, by maintaining flexibility to dynamically adapt roles, rules, } \\
\text { processes, and allowing exceptions from such if needed, and of } \\
\text { reaching a solid state, where such regulations are stable and recog- } \\
\text { nizable over a long period of time. }\end{array}$ \\
\hline 8 & US vs THEM & $\begin{array}{l}\text { When an OC interacts with external institutions (e.g. other commu- } \\
\text { nities, governments, political parties), it either receives or put pres- } \\
\text { sures on the environment, producing a tension, which in the end } \\
\text { may make the OC re-ensemble the environment. }\end{array}$ \\
\hline
\end{tabular}

Information and procedures involving issues like how to join the OC, which roles and responsibilities are present, and how to contribute may be transparent and clear to all members (and potential members) of the OC. On the contrary, some working dynamics and rules existing in the OC might be (deliberately or not) ambiguous and difficult to identify, making it more demanding for members (and interested persons) who do not know exactly what to do and how. OCs may then experience the tension of Transparency vs Obscurity.

Internal processes and routines may be rigid and enforcing, leaving OC members 
with no other alternative than to fulfil them before being able to take actions, then reinforcing processes certainty. On the contrasting side, some (or even all) processes and routines may stay flexible and liquid, allowing for freedom to bypass or dynamically change existing rules, or to create new ones. The OC is therefore under the influence of the Liquid vs Solid tension, and it should effectively balance the two states.

An OC has boundaries and an external environment, and works specifically to distinguish between what is part of the OC and what is external to it. The OCs for eParticipation relate to external entities, such as government organisations, political parties and other OCs. These relationships involve exchanges through communication and actions: here, there may be differences in how the OC works in relation to the external entities. An OC for eParticipation needs to communicate externally, with the need for creating and defending its own identity, and to interact with other institutions, with possible great differences in the respective ways of acting. Therefore, an OC is influenced by the tension $U s$ vs Them, with regards to how the OC relates with external entities and the environment.

\section{Discussing Tensions}

The M5S case shows that the interplay of large and complex OCs for eParticipation creates challenges and tensions. These tensions arise from: (i) the differences among values, rules, and routines internal to the community and that of the external environment that in our case is composed by the political institutions (tension 8); (ii) the different alternatives in terms of organizational arrangements of the interior of the OC (tensions 3 to 7); (iii) the different levels of commitment and motivation of OC members on the collective action (tension 1); and (iv) an externality of collective action (tension 2).

In the M5S case, the tension between the $\mathrm{OC}$ and the external environment is a consequence of a reciprocal effort to put pressure on each other, to let the other become more similar. The dynamics of this effort is in nature conflictual, up to the point that the isomorphism is seen also as a loss of identity. We assume that this originates in the organization of the political institutions, which includes units and groups in competition among themselves, so the loss of identity is a negative consequence that signals the defeat of the unit succumbing to the other in the competition. It is also important to point out that the M5S was born as a protest movement, and strong opposition to the political establishment is the glue that keeps the OC together. When internal competitions among organizational units is not in place, it should be investigated whether the management of the tensions between the community and the organization will still be conflictual or not.

The internal tensions relate to the different alternatives in terms of organizational arrangements of the OC. The literature stresses the need to structure the online community to have collective action [33-35]. However, due to the versatility of ICT, this can be realized in various ways. The different alternatives in the structuration of the internal processes supporting collective action (communication, contribution, decision-making models, and repertoire of contestations) give raise to tensions in the community as the 
results of different groups of members aiming for alternative ways of structuring.

The individual motivation is producing a tension in OC. The individual decision to contribute or not generates a fundamental tension in the OC, that of inertia vs action, which is a direct manifestation of the so called zero contribution thesis [23]. The M5S $\mathrm{OC}$ is designed to help citizens influence institutions by collecting ideas that, through the spokespersons, influence the political decision making processes. This depends on action of community member, while the lack of individual motivation may result in the lack of participation, giving rise to tensions among community members. Parties and movements rival to the M5S, take advantage of this by attempting to delegitimize action of the OC, arguing that this is not expression of the voluntary of a community, but the preference of a small number of individuals.

Finally, a tension relates to the externality of the collective action process. The literature on OCs is concerned with studying conditions that stimulates participation. These contributions praiseworthily aim at stimulating engagement by individuals, hence solving the inertia vs action tension. However, even in the presence of engagement, the OC is still under the tension of garbage vs content. In a mass size community like that of the M5S, a high level of engagement is a success indicator of the community. At the same time, a high level of engagement often leads to a high volume of useless actions and garbage, as members fail and producing a convergent result other than that of showing the presence on-line and declaring their support for the OC. Then, particularly in the case of OCs for eParticipation, it arises the need for a citizen-engagement strategy aimed at deriving more value from net-savvy citizens [36].

\section{Conclusion and further work}

The M5S' use of OC is a particularly interesting case to study for understanding eParticipation, because it sheds light on how an OC may address a huge number of citizens to create more participatory, open and transparent political discourses. Our case provides several evidences of the tensions that occur in OCs for eParticipation, because of their nature, their purposes and their organizational choices. Tensions are almost always inevitable for an OC, and often cannot be resolved permanently. Notwithstanding, to achieve its aims, an OC for eParticipation should find solutions to mitigate tensions' negative impact.

From the literature we learned that technologies used on OC have action capabilities that allow to achieve desired objectives [9]. An interesting avenue for further research is to investigate how mechanisms leveraging on such capabilities influence - reduce or increase - tensions within OCs. Issues to explore include how knowledge on tensions are broadening what we already know about dynamics of OC. On the same route, it will be important to raise implications for practice on how to balance these tensions within eParticipation projects. Future studies are needed also to better articulate how tensions may influence on OCs operating in the broader eGovernment area.

Another interesting suggestion for furthering research is the apparent commonality of many identified tensions also with OCs pertaining to domains different to eParticipation. Such suggestion asks for more study in various contexts. 


\section{References}

1. Medaglia, R.: eParticipation research: Moving characterization forward (2006-2011). Gov. Inf. Q. 29, 346-360 (2012).

2. Sæbø, Ø., Rose, J., Flak, L.: The shape of eParticipation: Characterizing an emerging research area. Gov. Inf. Q. (2008).

3. Rahman, M.M., Ahsan Rajoin, S.A.: An Effective Framework for Implementing Electronic Governance in Dveloping Countries: Bangladesh Perspective. Int. J. Comput. Inf. Technol. 3, 360-365 (2012).

4. Veit, D., Huntgerburth, J.: Foundations of Digital Government. Leading and Managing in the Digital Era. Springer-Verlag, Berlin, Heidelberg (2014).

5. Criado, J.I., Sandoval-Almazan, R., Gil-Garcia, J.R.: Government innovation through social media. Gov. Inf. Q. 30, 319-326 (2013).

6. Sæbø, Ø., Flak, L.S., Sein, M.K.: Understanding the dynamics in e-Participation initiatives: Looking through the genre and stakeholder lenses. Gov. Inf. Q. 28, 416-425 (2011).

7. Federici, T., Braccini, A.M., Sæbø, Ø.: "Gentlemen, all aboard!” ICT and party politics: Reflections from a Mass-eParticipation experience. Gov. Inf. Q. 32, 287-298 (2015).

8. Braccini, A.M., Federici, T., Sæbø, Ø.: Exploring Collective Action Dynamics in Online Communities from a Critical Realist Perspective. In: Blurring the Boundaries Through Digital Innovation. pp. 271-282. Springer International Publishing (2016).

9. Faraj, S., Jarvenpaa, S., Majchrzak, A.: Knowledge collaboration in online communities. Organ. Sci. 22, 1224-1239 (2011).

10. Majchrzak, A., Faraj, S., Kane, G.C., Azad, B.: The Contradictory Influence of Social Media Affordances on Online Communal Knowledge Sharing. J. Comput. Commun. 19, 38-55 (2013).

11. Kane, G.C., Johnson, J., Majchrzak, A.: Emergent Life Cycle: The Tension Between Knowledge Change and Knowledge Retention in Open Online Coproduction Communities. Manage. Sci. 60, 3026-3048 (2014).

12. Kollock, P., Smith, M.: Managing the Virtual Commons: Cooperation and Conflict in Computer Communities. In: Herring, S.C. (ed.) Computer-Mediated Communication: Linguistic, Social, and Cross-Cultural Perspectives. pp. 109-128. John Benjamins Publishing Company, Amsterdam/Philadelphia (1996).

13. Hutter, K., Hautz, J., Füller, J., Mueller, J., Matzler, K.: Communitition: The Tension between Competition and Collaboration in Community-Based Design Contests. Creat. Innov. Manag. 20, 3-21 (2011).

14. Huang, J., Baptista, J., Newell, S.: Communicational ambidexterity as a new capability to manage social media communication within organizations. J. Strateg. Inf. Syst. 24, 49-64 (2015).

15. Wahid, F., Sæbø, Ø.: Affordances and effects of promoting eparticipation through social media. In: Lecture Notes in Computer Science (including subseries Lecture Notes in Artificial Intelligence and Lecture Notes in Bioinformatics). pp. 3-14 (2015).

16. Majchrzak, a., Markus, M.L.: Technology Affordances and Constraints in Management Information Systems (Mis). Encycl. Manag. Theory. 5 (2012).

17. Preece, J.: Online Communities: Designing Usability and Supporting Socialbilty. (2000).

18. Olson, M.: The logic of collective action. Harvard University Press (2009).

19. Flanagin, A.J., Stohl, C., Bimber, B.: Modeling the Structure of Collective Action. Commun. Monogr. 73, 29-54 (2006).

20. Dellarocas, C.: Strategic Manipulation of Intenret Opinion Forums: Implications for Consumers and Firms. Manage. Sci. 52, 1577-1593 (2006).

21. Leidner, D.E., Kock, H., Gonzalez, E.: Assimilating Generation Y IT New Hires into 
USAA's Workforce: The Role of an Enterprise 2.0 System. MIS Q. Exec. 9, 229-242 (2010).

22. Wasko, M.M., Faraj, S.: Why Should I Share? Examining Social Capital and Knowledge Contribution in Electronic Networks of Practice. MIS Q. 29, 35-57 (2005).

23. Ostrom, E.: Collective Action and the Evolution of Social Norms. J. Econ. Perspect. 14, $137-158$ (2000).

24. Ostrom, E.: Governing the Commons. (1990).

25. Ribes, D., Finholt, T. a.: The Long Now of Technology Infrastructure: Articulating Tensions in Development. J. Assoc. Inf. Syst. 10, 375-398 (2009).

26. Krogh, G. von, Haefliger, S., Spaeth, S., Wallin, M.: Carrots and rainbows: Motivation and social practice in open source software development. Mis Q. 36, 649-676 (2012).

27. Ågerfalk, P.J., Fitzgerald, B.: Outsourcing to an Unknown Workforce: Exploring Opensourcing as a Global Sourcing Strategy. MIS Q. 32, 385-409 (2008).

28. O'Reilly, C.A.I., Tushman, M.L.: Organizational Ambidexterity: Past, Present, and Future. Acad. Manag. Perspect. 27, 324-338 (2013).

29. Sæbø, Ø., Braccini, A.M., Federici, T.: From the blogosphere into real politics: The use of ICT by the five star movement. In: Mola, L., Pennarola, F., and Za, S. (eds.) Lecture Notes in Information Systems and Organisation. pp. 241-250. Springer International Publishing, Cham (2015).

30. Eisenhardt, K.M.: Building Theories from Case Study Research. Acad. Manag. Rev. 4, 532-550 (1989).

31. Corbin, J., Strauss, A.: Basics of Qualitative Research. Techniques and Procedures for Developing Grounded Theory. SAGE Publications Inc., Thousand Oaks, California (2015).

32. Bekkers, V., Edwards, A., de Kool, D.: Social media monitoring: Responsive governance in the shadow of surveillance? Gov. Inf. Q. 30, 335-342 (2013).

33. Braccini, A.M., Federici, T., Sæbø, Ø.: Exploring Collective Action Dynamics in Online Communities from a Critical Realist Perspective. In: D'Ascenzo, F., Magni, M., Lazzazzara, A., and Za, S. (eds.) Blurring the Boundaries Through Digital Innovation. pp. 271-282. Springer (2016)

34. Federici, T., Braccini, A.M., Sæbø, Ø.: “Gentlemen, all aboard!” ICT and party politics: Reflections from a Mass-eParticipation experience. Gov. Inf. Q. 32, 287-298 (2015).

35. Sæbø, Ø., Braccini, A.M., Federici, T.: From the Blogosphere into Real Politics: The Use of ICT by the Five Star Movement. In: Mola, L., Pennarola, F., and Za, S. (eds.) From Information to Smart Society - Environment, Politics and Economics. pp. 241250. Springer International Publishing, Cham (2015).

36. Chatfield, A.T., Scholl, H.J. (Jochen), Brajawidagda, U.: Tsunami early warnings via Twitter in government: Net-savvy citizens' co-production of time-critical public information services. Gov. Inf. Q. 30, 377-386 (2013). 